\title{
Sömürge Para Sisteminin Ekonomik Etkileri: CFA Frangı ve Afrika Ülkeleri Üzerine Bir İnceleme
}

\author{
Jaures Badet $i D$ \\ Yüksek Lisans Öğrencisi, Necmettin Erbakan Üniversitesi, Sosyal Bilimler Enstitüsü, İktisat, Konya, Türkiye,
} dulambadet@gmail.com (Sorumlu Yazar/Corresponding Author)

\begin{tabular}{|c|c|}
\hline Makale Bilgileri & ÖZ \\
\hline $\begin{array}{l}\text { Anahtar Kelimeler: } \\
\text { Sömürge para } \\
\text { sistemleri, Ekonomik } \\
\text { Büyüme, Afrika } \\
\text { Kolonileri, CFA Frang1, } \\
\text { Euro. } \\
\text { JEL Kodları: E1, E42, } \\
\text { O1. }\end{array}$ & $\begin{array}{l}\text { Ülkeler ekonomik istikrar, büyüme ve malların serbest dolaşımını sağlamak amacıyla konvertibilitesi } \\
\text { olan paralar kullanmaktadır. Bu para sistemleri ve uygulanan para politikaları ekonomik sistem } \\
\text { içerisinde bazı ülkeler için bir avantaj oluştururken, zaman zaman bazı ülkelerin ekonomik } \\
\text { gelişimlerinin önünde bir engel teşkil edebilmektedir. Afrika Kolonileri Frangı olarak da bilinen } \\
\text { CFA Frangı, geçmişte Orta ve Batı Afrika bölgelerinde kullanılan bir para birimi olmuştur. } \\
\text { Geçtiğimiz yetmiş beş yılın ardından, CFA Frangı halen Afrika'nın } 14 \text { ülkesinde ve Komorlar 'da } \\
\text { kullanılmaktadır. Afrika para birimi olan CFA Frangının Euro ile konvertibilitesini kontrol altına } \\
\text { alan ülke Fransa'dır. Bu para sisteminin amacı, genel ilkelere dayanarak, büyümeyi artırmak yerine } \\
\text { CFA ülkelerinin mali durumlarını istikrara kavuşturmak olarak belirlenmiştir. Bu kapsamda, CFA } \\
\text { Frangı kullanan } 13 \text { ülkenin IMF tarafından düşük gelirli ve borç içinde olan ülkeler olarak } \\
\text { sınıflandırıldığı görülmektedir. Bu çalışmada CFA Frangı para sisteminin Afrika ülkeleri üzerindeki } \\
\text { ekonomik etkilerinin incelenmesi amaçlanmıştır. CFA frangı sistemiyle ilgili veri ve bilgilere dayalı } \\
\text { olarak araştırma yapılmaktadır. CFA frangı kullanan ülkelerdeki mevcut ekonomik durumu analiz } \\
\text { etmek için ekonomik büyümeye ve bu ülkelerin ekonomi politikalarına ilişkin veriler incelenmiştir. } \\
\text { Üye ülkelerin ekonomik durumlarının üye olmayan ülkelerle karşılaştırılması da yapılmıştır. } \\
\text { UEMOA bölgesi ülkeleri ekonomik olarak CEMAC bölgesi ve Komorlar'dan biraz daha istikrarlı } \\
\text { olsalar bile, frank bölgesindeki durumun biraz kritik olduğu görülmektedir. Afrika'daki ilk } 20 \text { yüksek } \\
\text { GSYİH ülkesinde sadece dört frank bölge ülkesi vardır. Ayrıca Gabon ve Ekvator Gine'si dışında, } \\
\text { frank bölgesindeki tüm ülkelerin ağır borçlu yoksul ülkeler grubuna ve IDA desteği için uygun } \\
\text { ülkeler grubuna dahil olduğu görülmektedir. Ayrıca, Birleşmiş Milletler'in en az gelişmiş } 46 \\
\text { ülkesinden dokuzu frank bölgesindendir ve frank bölgesindeki } 13 \text { ülke, düşük insani gelişmeye sahip } \\
\text { ülkeler grubunun bir parçasıdır. }\end{array}$ \\
\hline
\end{tabular}

Economic Effects of the Colonial Money System: a Review on the CFA Franc and African Countries

\begin{tabular}{|c|c|}
\hline Article Info & ABSTRACT \\
\hline $\begin{array}{l}\text { Article History } \\
\text { Received: } 09.12 .2020 \\
\text { Accepted: } 29.03 .2021 \\
\text { Published: } 30.06 .2021 \\
\text { Keywords: } \\
\text { Colonial money } \\
\text { systems, Economic } \\
\text { Growth, African } \\
\text { Colonies, CFA Franc, } \\
\text { Euro. } \\
\text { JEL Codes: E1, E42, } \\
\text { O1. }\end{array}$ & $\begin{array}{l}\text { Countries use convertible currency systems to ensure economic stability, growth and the free flow } \\
\text { of goods. These monetary systems and monetary policies are an advantage for some countries, but } \\
\text { they can sometimes constitute an obstacle to the economic development of other countries. Also } \\
\text { known as the African Colonial Franc, the CFA franc is a currency used in parts of Central and West } \\
\text { Africa in the past. After seventy-five years of its creation, the CFA franc is still used in } 14 \text { countries } \\
\text { in Africa and the Comoros. The country that controls the convertibility of the CFA franc, which is } \\
\text { an African currency, along with the Euro, is France. The goal of this monetary system, based on } \\
\text { general principles, promotes the stability of the financial situation of user countries instead of } \\
\text { increasing growth. In this context, we see that } 13 \text { countries using the CFA franc are classified by the } \\
\text { IMF as low income countries and as indebted countries. The aims of this paper is to analyze the } \\
\text { economic effects of the CFA franc monetary system on African countries. Research-based on data } \\
\text { and information relating to the CFA franc system are carried out. To analyze the current economic } \\
\text { situation in the countries using the CFA franc, data relating to economic growth, to the economic } \\
\text { policies of these countries was examined. A comparison of the economic situation of member } \\
\text { countries with non-member countries was also made. We find that even if the countries of the } \\
\text { UEMOA zone are a little more stable economically than the CEMAC zone and Comoros, the } \\
\text { situation in the franc zone is somewhat critical. There are only four franc zone countries in the top } \\
20 \text { high GDP countries in Africa. We also find that except Gabon and Equatorial Guinea, all countries } \\
\text { in the franc zone are included in the group of heavily indebted poor countries and the group of } \\
\text { countries eligible for IDA support. Also, among the } 46 \text { least developed countries of the United } \\
\text { Nations, nine were from the franc zone and } 13 \text { countries in the franc zone are part of the group of } \\
\text { countries with low human development. }\end{array}$ \\
\hline
\end{tabular}

Atıf/Citation: Badet, J. (2021). Sömürge Para Sisteminin Ekonomik Etkileri: CFA Frang1 ve Afrika Ülkeleri Üzerine bir İnceleme, Necmettin Erbakan Üniversitesi Siyasal Bilgiler Fakültesi Dergisi, 3(1), 36-51. 


\section{GİRIŞ}

Kolonilerin para birimleri üzerindeki sömürgeci kontrolünü güçlendirmek için 1945'te Fransa tarafindan CFA (Franc des Colonies Françaises d'Afrique) frang1, para birimi olarak oluşturulmuştur. İlk olarak, Afrika'nın Fransız Kolonisi olan CFA, 1958'de Afrika Topluluğunun Frang1 olmuştur. Bağımsızlıktan sonra, frank bölgesi küçülmüştür. CFA frangı, bugün UEMOA ${ }^{1}$ içinde birleştirilen Batı Afrika ülkelerinde Afrika Finans Topluluğu Frang1, CEMAC ${ }^{2}$ bünyesinde birleştirilen Orta Afrika ülkeleri için Orta Afrika'da Finansal İşbirliği ve Komor Cumhuriyetinden oluşmaktadır. İlk olarak, CFA frangı ile Fransız Frangı (FF) arasında sınırsız dönüştürülebilirlik sağlanmıştır. Ancak 1999'dan itibaren Fransa'nın Euro'ya geçişi ile oranlar değişmiştir. Günümüzde CFA frang1, Senegal, Mali, Nijer, Burkina Faso, Benin, Togo, Fildişi Sahili, Gine-Bissau, Çad, Kamerun, Ekvator Gine'si, Gabon, Kongo, Orta Afrika olarak 14 ülke ve Komorlar tarafından kullanılmaktadır.

Küresel para savaşı bağlamında, tartışmalar 14 Afrika ülkesinde kullanılan bu ortak para biriminin korunmasının önemli olup olmadığına dairdir. CFA Frangının geleceğinin sorgulanması son yıllarda artmaktadır. $\mathrm{u}$ tekrarlayan eleştirinin birkaç nedeni vardır. Bunlardan birisi üye ülkelerin dolaşımdaki para birimi üzerinde kontrol sahibi olmalarına izin vermeyen parasal bağımlılıktır ${ }^{3}$ Bu onların sürdürülebilir bir ekonomi politikası uygulamalarını engellemektedir. Fransa'nın frank bölgesinin üye devletleri üzerindeki hakimiyeti ve kontrolü gibi diğer birçok sebep bulunmaktadır. Literatürde, CFA frangı ile ilgili yapılan çok sayıda çalışmanın ( Coquet ve Daniel, 1992; Diallo, 2002; Tchouassi, 2016; Claveres, 2017; Jacquemot, 2017; Avom ve Noumba, 2019; Kebe, 2019) var olduğu görülmektedir. Bu çalışmaların çoğunda, üye ülkeler tarafından CFA Frangının kullanımına ve bu ülkelerin ekonomisi üzerindeki avantaj ve dezavantajlarına ilişkin eleştirilere odaklanılmaktadır.

$\mathrm{Bu}$ çalışmada CFA frangı para sisteminin Afrika ülkeleri üzerindeki ekonomik etkilerinin incelenmesi amaçlanmıştır. Çalışmada ilk olarak tarihsel süreçte sömürge para sistemleri irdelenmiştir. Daha sonra CFA frangı para sisteminin nasıl çalıştığı üzerinde durulmakta ve CFA Frangı kullanan ülkelerde mevcut ekonomik durum ile CFA frangının kullanıcı ülke ekonomileri kapsamındaki avantajları ve dezavantajları açıklanmaktadır. Son bölümde CFA frangı para sisteminin ekonomik etkilerine ilişkin genel bir değerlendirmeye yer verilmektedir.

\section{TARİHSEL SÜREÇTE SÖMÜRGE PARA SISTEMLERİ}

CFA frangının 1945 'teki kuruluşundan bu yana tarihsel sürecini kısaca özetleyecek olursak; 1945 'ten önce Afrika'da yerel, geleneksel ve ilkel para birimleri (cowries, giysi, tuz, aletler veya silahlar) takas aracıları olarak kabul edilir ve işlem yapmak için kullanılırdı (Servet, 2012). Bununla birlikte, 1920'lerin başlarında, Fransız para birimi Fransa ve sömürgeleri arasındaki para birliği olarak tamamlanmış ancak henüz resmileştirilmemiştir. 1930'larda Fransa bu kolektifin homojenliğini azaltmıştır. Uluslararası ticaretin çöküşü ve uluslararası para sisteminin parçalanmasıyla karşı karşıya kalan Fransa ve İngiltere, sömürge devletlerinin ekonomisini daha kolay izlemeye ve desteklemeye çalışmıştır (Lelart, 1985). Parasal bağlar, sömürgeleştirici ülkelerin çeşitli başkentleri ile sömürgeler arasında daha da büyümüştür. Çok sayıda para birimi ile karşs karşıya kalan ulus devletler, 19. yüzyılda, merkezi otoriteleri tarafindan kabul edilmeyen para birimlerini (yabancı para birimleri, yerel para

\footnotetext{
${ }^{1}$ Union Economique et Monétaire Ouest Africaine (Bat1 Afrika Ekonomik ve Parasal Birliği)

${ }^{2}$ Communaute Economıque et Monetaire de l'Afrıque Centrale (Orta Afrika Ekonomik ve Parasal Topluluğu)

${ }^{3}$ Bir ülkenin kendisine ait olmayan para birimine bağlı olması. Söz konusu ülke değişen koşullarda ülkenin çıkarları doğrultusunda para birimi üzerinde düzenleme yapamamaktadır.
} 
birimleri, banknotlar) kaldırarak ve ortak bir para birimi kurarak parasal alanlarının homojenleşmesine devam etmişlerdir. Tüm bu düzenlemelerin amacı uluslararası para borsalarını düzenlemek olan uluslararası bir para sisteminden ayrılacak ulusal bir para sistemi yaratmaktır (Tchouassi, 2016: 3-4). Böylece koloniler üzerinde kontrol sahibi olmak için, para birimi olarak CFA frang1 26 Aralık 1945'te Fransa tarafından tek yasal para birimi olarak oluşturuldu. 1958'deki bağımsızlık günlerinde, CFA frang1, tarihinde başka bir dönüm noktası yaşayacak ve Afrika Fransız Topluluğunun Frang1 "Franc de la Communauté Française d'Afrique" olacaktır. 1960 yılında, frank bölgesinin tüm Afrika Devletleri bağımsızlıklarını elde etmişlerdir. Bağımsızlıktan sonra bile, frank bölgesinin tüm ülkeleri, CFA frangını 1960'da Gine ve 1962'de Mali hariç bir döviz para birimi olarak tutmaya karar vermiştir. Frank bölgesinde kalan Devletler için iki bağımsız para birimi oluşturulmuştur. Bunlar U.M.O.A. Batı Afrika Devletleri Para Birliği "Union économique et monétaire Ouest-Africaine" 1962'de ve U.M.A.C Orta Afrika Para Birliği "Union économique et Monétaire de l'Afrique Centrale" 1972'de kurulmuşlardır. Frank bölgesinin kurumsal merkezi Fransa'da bulunmaktadır ve frank bölgesindeki maliye bakanları 1965 'ten beri Paris'te altı ayda bir toplanmaktadır (Kebe, 2019a: 18).

Para sistemine ilişkin 1980'ler ve 1990'larda, değişiklikler ve ayarlamalar yapılmıştır. Bu dönem, Mali'nin 1984'te frank bölgesine yeniden entegrasyonu ve 1985'te Ekvator Gine'si ve 1997'de GineBissau'nun dahil edilmesi ile dikkat çekmiştir. Ek olarak, U.M.O.A, U.E.M.O.A. Batı Afrika Ekonomik ve Parasal Birliği "Union Economique et Monétaire Ouest-Africaine" ve U.M.A.C, C.E.M.A.C. Orta Afrika Ekonomik ve Parasal Topluluğu "Communauté Economique et Monétaire de l'Afrique Centrale" olmaktadır. 1999'da Euro'nun gelişi CFA frangını 656 CFA frangına sabitlenmiştir (1 Euro $=656$ CFA Frang1) (Kebe, 2019b: 20-22).

Frank bölgesinden ayrılan ve daha sonra geri dönen ülkeler dışında, bazı ülkelerin bağımsızlık sırasında veya sonrasında sömürge frank bölgesini kesin olarak terk etmeyi seçtiklerini belirtmek önemlidir. 1963'te Cezayir, 1959'da Fas, 1958'de Tunus, 1973'te Moritanya, 1973'te Madagaskar, 1954'te eski Çinhindi (Kamboçya, Laos, Vietnam) gibi ülkeler örnek gösterilmektedir. Tablo 1 CFA frangının tarihsel kriterlerini göstermektedir.

Tablo 1. CFA frangi'nin tarihsel kriterleri

\begin{tabular}{|l|l|}
\hline Yıl & CFA frang'nın tarihsel kriterleri \\
\hline 1929 & $\begin{array}{l}\text { Yerel para emisyonunun tekellerine sahip olan sömürge enstitüleri yenilenmiştir. Bundan } \\
\text { böyle faaliyetleri özellikle kredi ve para politikası ile ilgili sıkı bir şekilde kontrol edilecektir. } \\
\text { Bu andan itibaren para birimleri, 1928'den beri genellikle metropol para biriminin tüm } \\
\text { devalüasyonlarını takip edecekleri için Fransız frangı üzerine sabitlenir. }\end{array}$ \\
\hline 1936 & $\begin{array}{l}\text { Frank, altına göre tanımlanmaktan vazgeçilir. Döviz sabitleme fonunun oluşturulmasıdır. } \\
\text { Sömürgeci ihraç eden bankalar, parasal yaratımlarını Fransız Frangı rezervleri ile karşılama } \\
\text { hakkına sahip olurlar ve bunlar daha sonra para birimlerine asimile edilir. }\end{array}$ \\
\hline 1939 & $\begin{array}{l}\text { Tüm Fransız sömürge bölgelerinde ortak olan değişim düzenlemelerinin tanıtılmasıdır. Savaş } \\
\text { ilanı, dış ticaret ve sermaye hareketleri üzerinde sıkı kontrollerin uygulanmasıyla } \\
\text { örtüşmektedir. Frank bölgesi, resmi bir varlık kazanır, çünkü ona bağlı olan frangı ve para } \\
\text { birimleri serbestleştirici güce sahiptir ve bölge içinde aktarılabilir, yabancı rezervlerin birlikte } \\
\text { yönetildiği ve ortak bir düzenleme olduğu değiş tokuştur. }\end{array}$ \\
\hline
\end{tabular}




\begin{tabular}{|c|c|}
\hline 1940 & $\begin{array}{l}\text { 1945'e kadar Fransa'daki işgal, Fransa anakarasında ve Vichy hükümetiyle toplanan bölgelerde } \\
\text { parasal ayaklanmalara neden oldu. } \\
\text { Yavaş yavaş Müttefiklere katılacak olan Fransız kolonilerinde geçiş sistemleri kuruldu. Savaş } \\
\text { sırasında bölgenin para birimlerinin pariteleri birkaç kez değiştirilecektir. }\end{array}$ \\
\hline 1945 & $\begin{array}{l}\text { Savaş sırasında, Müttefiklere katılan kolonilerin ticari alışverişleri sadece İngiltere ve ABD } \\
\text { başta olmak üzere bu ülkelere doğru gerçekleştirildi. Buna ek olarak, Fransız toprakları farklı } \\
\text { makroekonomik gelişmeler yaşamıştır. Bu durumu düzeltmek için sömürge Frangı yaratıldı. } \\
\text { CFP frangı Pasifik kolonilerinde tanıtıldı; değeri başlangıçta doların değerine endekslendi. } \\
\text { CFA frangı Tunus, Cezayir, Fas, Fransa, Guyana ve Antiller hariç diğer tüm bölgelerde } \\
\text { kurulmuştur. Sonraki yıllarda, bu para birimlerinin değeri birkaç kez değiştirilecektir. }\end{array}$ \\
\hline 1946 & $\begin{array}{l}\text { Bölgede sermayenin hareketine geçici olarak getirilen kısıtlamalar kaldırılmıştır. Bu tarihten } \\
\text { itibaren parasal konuların imtiyazı kademeli olarak kamu kurumlarına emanet edilecektir. }\end{array}$ \\
\hline 1948 & $\begin{array}{l}\text { Sömürge bölgelerinden gelen ticaret akımları Fransa'ya tamamen odaklandı. Sömürge frang1 } \\
\text { değerleri mevcut oranlarda dondurulur. Daha sonra değerleri değiştirilmeyecektir. Frank } \\
\text { bölgesi mükemmel parasal homojenlik bulur. }\end{array}$ \\
\hline 1955 & $\begin{array}{l}\mathrm{AEF}^{4} \text { ve } \mathrm{AOF}^{5} \text { için özel kuruluşların oluşturulmasıdır. Her birinin Fransız Hazinesi ile } \\
\text { Madagaskar, Fas ve Outre-Mer'deki Fransa Merkez Fonu için deneyimlendiği gibi bir işletme } \\
\text { hesabı vardır. }\end{array}$ \\
\hline 1957 & Fas, Fas Bankası'nı oluşturur ve frank bölgesinden ayrılır. \\
\hline 1958 & $\begin{array}{l}\text { Fransız topraklarındaki kamu yatırımlarının finansmanından münhasıran sorumlu olan CCCE, } \\
\text { kademeli olarak eski imtiyazlarından yoksun bırakılan CCFOM'un yerini almaktadır. Tunus } \\
\text { kendi merkez bankasını kurar ve bölgeyi terk eder. }\end{array}$ \\
\hline 1959 & $\begin{array}{l}\text { AEF ve AOF enstitüler merkez bankaları olur: } \text { BCEAC }^{6} \text { ve } \text { BCEAO }^{7} \text {. Onların imtiyazları } \\
\text { temelden değiştirilmemiştir. Yavaş yavaş ulusal para komiteleri kurulmuştur, } 1965 \text { 'te her } \\
\text { katılımcı ülkede bir tane vardı. }\end{array}$ \\
\hline 1960 & $\begin{array}{l}\text { Franco-Afrika topluluğuna katılmayı reddetmesinin mantığında, Gine (Conakry) frank } \\
\text { bölgesinden ayrılmaktadır. }\end{array}$ \\
\hline 1962 & $\begin{array}{l}\text { Fildişi Sahili, Dahomey, Yukarı Volta, Moritanya, Nijer ve Senegal UMOA'yı yaratıyor. Mali } \\
\text { frank bölgesinden ayrılır. Para birlikleri ve Fransa arasındaki işbirliği anlaşmaları, bölgedeki } \\
\text { merkez bankalarının işletme yöntemlerinde büyük değişiklikler getirmektedir. }\end{array}$ \\
\hline 1963 & $\begin{array}{l}\text { Bağımsızlığını takiben Cezayir, diğer Mağrip ülkelerinin yolunu izledi, kendi merkez } \\
\text { bankasını kurdu ve bölgeyi terk etti. Togo UMOA'ya katıldı. }\end{array}$ \\
\hline 1967 & Mali, frank bölgesine geri döner. \\
\hline 1972 & $\begin{array}{l}\text { Bir yandan Fransa ve BEAC bölgesi arasında ve diğer yandan bu bölge ülkeleri arasında } \\
\text { parasal anlaşmalar yapılırken BCEAC } \mathrm{BEAC}^{8} \text { olur. } \mathrm{Bu} \text { nedenle çalışma modları }\end{array}$ \\
\hline
\end{tabular}

${ }^{4}$ Afrique Equatoriale Française (Fransız Ekvatoral Afrika).

${ }^{5}$ Afrique Occidentale Française (Fransız Batı Afrika).

6 Banque Central des Etats de l'Afrique Centrale (Orta Afrika Devletleri Merkez Bankası).

7 Banque Centrale des Etats de l'Afrique de l'Ouest (Batı Afrika Devletleri Merkez Bankası).

${ }^{8}$ Banque des Etats de l'Afrique Centrale (Orta Afrika Devletleri Bankası). 


\begin{tabular}{|c|c|}
\hline & $\begin{array}{l}\text { değiştirilmiştir; aynı zamanda ulusal para komiteleri elden geçirilmiştir. Moritanya Frank } \\
\text { bölgesinden ayrılır. }\end{array}$ \\
\hline 1973 & $\begin{array}{l}\text { BCEAO statüleri ve çalışma kuralları değiştirilmiştir. Ulusal para komitelerinin yetkileri } \\
\text { değiştirilir ve bu organlar ulusal kredi komiteleri haline gelir. 1970'lerin başlarındaki bu } \\
\text { reform dalgasından sonra, emisyon kurumların yetkileri ve bölgedeki yürürlükteki kurallar } \\
\text { ancak çok az değişecektir. } \\
\text { Madagaskar bölgeyi terk etmiştir. }\end{array}$ \\
\hline 1975 & Bağımsızlıklarının ardından, Komorlar frank bölgesinde kalmıştır. \\
\hline 1979 & Komorların emisyon enstitüsü merkez bankası olur. \\
\hline 1983 & Mali'nin UMOA'ya yeniden entegrasyonu. \\
\hline 1985 & Ekvator Ginesi frank bölgesine entegre edilmiştir. \\
\hline
\end{tabular}

Kaynak: Coquet ve Daniel, 1992: 243-244.

\section{CFA FRANGI PARA SISTEMI}

Kolonilerinin para birimi üzerinde metropolün kontrolünü güçlendirmek için Fransa 1939'da Frank bölgesini yaratmıştır. Frank bölgesi, hammaddelerin savaş zamanında daha istikrarlı fiyatlarda sağlanmasını kolaylaştırmak amacıyla oluşturulmuştur. Frank bölgesinde 14 Afrika ülkesi ve Komorlar bulunmaktadır. Komorlar'ın adlandırdığı “Komorlar frangı” kendi para birimidir.

\section{CFA Frangı Nasıl Çalışır?}

Frank bölgesi iki CFA frangı ve iki merkez bankasının kullanıldığı bir alandır. UEMOA bölgesindeki CFA frangından sorumlu olan Senegal merkezli Batı Afrika Eyaletleri Merkez Bankası "Banque centrale des Etats d'Afrique de l'Ouest" (BCEAO) ve CEMAC bölgesindeki CFA frangından sorumlu olan Yaoundé (Kamerun) merkezli Orta Afrika Devletleri Bankasıdır "Banque des Etats d'Afrique centrale" (BEAC). Bu iki banka Fransa hükümeti ile iş birliği içindedir. Frank bölgesinin üye ülkelerinin ulusal bir merkez bankası bulunmamaktadır. Üye ülkelerin parasal egemenliklerinin olmaması nedeni ile para birimi üzerinde kontrolleri yoktur.

Her bölgedeki ticari bankalar doğrudan para birlikleri merkez bankasının kontrolü altındadır. Parasal birliklerin her bir merkez bankası, Fransız Hazine Müsteşarlığının gözetimine alınır ve orada cari bir hesabı vardır. Bu işletme hesabı, Frank bölgesinin tüm merkez bankalarından (Fransa Bankası hariç) döviz varlıklarını almalıdır. İşletme hesabı ayrıca kredi veya borç olabilir. Bu bakiyeler sözleşmeye bağlı olarak, hesaplama yöntemi sermaye piyasasında yürürlükte olanlara karşılık gelen oranlarda faiz ödemelerine tabidir. Bir açık olması durumunda, işletme hesabı bakiye geri yüklenene kadar Fransız Hazinesi tarafından beslenir. Bu, hesabın borç bakiyesinin teorik olarak tutarı veya süresi ile sınırlı olmadığı anlamına gelir. Bununla birlikte, bir açığın ortaya çıkması, onu azaltmak için uygun bir para politikasının uygulanmasına yol açmalıdır. Bu önlemlere ek olarak, işletme hesabı aracıllı̆ıyla Fransız Hazinesi tarafından sağlanan otomatik finansman maliyeti vardır (Coquet ve Daniel, 1992: 245).

\section{Frank Bölgesi Ülkeleri}




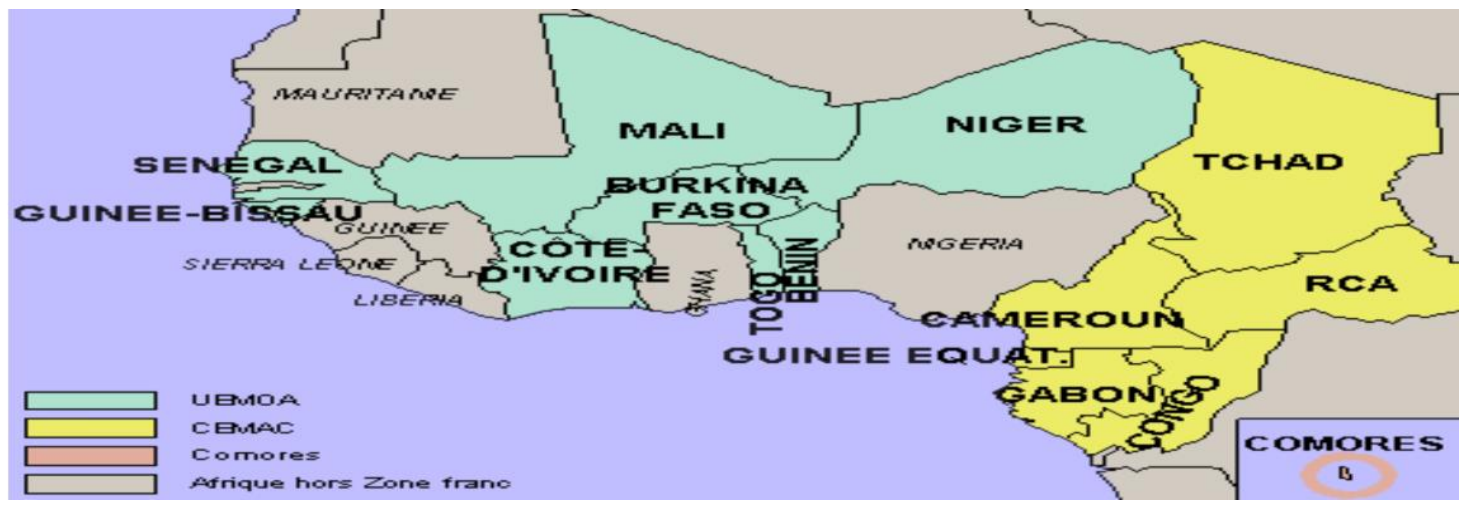

Şekil 1. Frank bölgesi ülkeleri

Kaynak: Banque de France,2016

Frank bölgesi ülkeleri Senegal, Mali, Nijer, Burkina Faso, Benin, Togo, Fildişi Sahili, GineBissau, Çad, Kamerun, Ekvator Gine'si, Gabon, Kongo, Orta Afrika ve Komorlardır. Yeşil renkli bölge UEMOA içinde birleşmiş ülkeleri ve sarı renkli bölge CEMAC içinde birleşmiş ülkeleri temsil etmektedir. Pembe renkli bölgede ise Komorlar yer almaktadır. Senegal, Mali, Gine Bissau, Fildişi Sahili, Burkina Faso, Benin, Togo ve Nijer UEMOA içinde birleşmiş ülkelerdir. Çad, Kamerun, Ekvator Gine'si, Gabon, Kongo ve Orta Afrika CEMAC içinde birleşmiş ülkelerdir. Bağımsızlıktan sonra 1960'ta UEMOA içinde birleşmiş batı Afrika ülkelerinde, CFA frangı Afrika Fransız Topluluğunun Frang1 (Franc de la Communauté Française d'Afrique) olurken CEMAC içinde bulunmuş Orta Afrika ülkelerinde Orta Afrika'daki Mali İşbirliğinin Frangı (Franc de la Coopération Financière en Afrique centrale) olmaktadır. Frank bölgesi Komorlar ve üç Pasifik bölgeden (Fransız Polinezya'sı, Wallis ve Futuna, Yeni Kaledonya) oluşmaktadır.

\section{CFA frangı, Komor frangı ve Euro arasındaki bağlantı}

İç hukukta, uluslararası hukukta olduğu gibi, parayı basma gücü Devletin egemenliğine bağlı bir ayrıcalıktır (Diallo, 2002: 2). En eski zamanlardan beri devlet, paranın değerinin ve dolaşımının düzenlenmesini münhasır hakk1 olarak görmüştür (Sulkowski, 1929: 30-31). Böylece çalışmanın bu bölümünde CFA frangı, Komor frangı ve Euro arasındaki ilişki tartışılmıştır.

1 Ocak 1999'da Euro, Avrupa Ekonomik ve Parasal Birliği üyelerinden on bir Avrupa ülkesinin para birimi olmuş ve Fransız Frangı Euro'nun ondalık olmayan bir alt bölümü haline gelmiştir. Euro, CFA frang1 ve Komor frang1, Fransız Frang1 ile değiştirilmiştir. Bu ikame otomatik olarak CFA frang1 ve Komor frangı Euro paritelerini belirlemiştir. Bu pariteler frank Bölgesi'nin parasal iş birliği mekanizmalarını etkilememektedir. Euro'ya bağlanma CFA ve Komor frang1 paritelerinde bir değişikliğe yol açmamış: 31 Aralık 1998'de Avrupa Birliği Konseyi, Euro ile Fransız Frangı arasındaki dönüşüm oranını sabitlemiştir $(1$ Euro $=6.55957 \mathrm{FF})$. Bu oran, Euro'nun CFA frang1 ve Comorian frang1 içindeki değerini otomatik olarak belirlemiştir. CFA frang1 1 Fransız Frangı için 100 FCFA oranında değiştirildiğinden, CFA frang1 paritesi günümüzde 1 Euro = 655.957 CFA frangıdır. Benzer şekilde, Comorian frang1 1 Fransız Frangı için 75 FC oranında değiştirildiğinden paritesi günümüzde 1 Euro 491.96775 CFA frangıdır. Euro'nun Fransız Frangı yerine CFA frangı ve Comorian frangı parasal çapası olarak kullanılmasıyla bu para birimlerinin paritesinde herhangi bir değişikliğe yol açmamıştır. $\mathrm{Bu}$ gelişmelerle frank bölgesindeki parasal anlaşmaların sürekliliği sağlanmıştır: Fransa'yı frank bölgesinin diğer ülkelerine bağlayan parasal iş birliği anlaşmaları avroya geçişten etkilenmemektedir. Fransız ve Afrika makamları, tek para birimine geçme kararından bu yana frank Bölgesi anlaşmalarını korumaya karar vermişlerdir (Banque de france,2016). 
Fransa ve frank bölgesi anlaşmalarını imzalayan diğer ülkeler bunların uygulanmasından tek başına sorumludur. Bu, özellikle Euro ile CFA ve Comorian frangı arasındaki paritedeki değişikliklerin frank bölgesi üye devletlerinin sorumluluğunda olduğunu göstermektedir. Bununla birlikte, Fransız makamları, parite değişikliklerinden önce Avrupa Birliği Ekonomik ve Mali Komitesini (CEF) bilgilendirmeli ve bu komisyon da BCE ve CEF'yi anlaşmaların uygulanması hakkında düzenli olarak bilgilendirmelidir. Avrupa Birliği Konseyi'nin kararı sadece iki durumda gereklidir: sözleşmelerin kapsamı değiştiğinde (yeni bir Devletin kabulü) veya sözleşmenin niteliği değiştirildiği zaman (örneğin, Fransız Devleti tarafından teminat prensibi sabit oranlı CFA ve Komor frangı dönüştürülebilirliği). Diğer herhangi bir değişiklik, frank bölgesi üye devletlerinin münhasır yetkisi olmaya devam etmektedir (Banque de france, 2016).

\section{Frank bölgesinin ilkeleri}

Günümüzde Frank Bölgesi ile ilgili eylemlerde bulunan kurucu ilkeleri yani 1972 ve 1973 sözleşmelerini özetleyecek olursak; (Avom ve Noumba, 2019: 9-10)

$\checkmark \quad$ Konvertibilite garantisi: Fransız kamu hazinesi, CFA ve Komor franklarının herhangi bir para biriminde dönüştürülebilirliğini garanti etmektedir.

$\checkmark \quad$ Parçanın sabit para birimi ile sabitliği: CFA veya Comorian frangı ile Euro arasındaki parite oranı sabittir. 1 EUR $=655.957$ CFA frangıdır.

$\checkmark \quad$ Serbest transfer edilebilirlik: frank bölgesindeki sermaye transferleri tamamen serbesttir.

$\checkmark \quad$ Döviz rezervlerinin merkezileştirilmesi: CFA frang1 kullanan ülkelerdeki merkez bankaları, döviz rezervlerinin \% 50'sini Fransız hazinesine yatırmalıdır.

\section{CFA FRANGI KULLANAN ÜLKELERDE MEVCUT EKONOMIKK DURUM}

CFA frangı kullanan ülkelerin ekonomik durumlarının incelemesinde ilk olarak UEMOA'nın ekonomik durumu, sonra CEMAC'in ekonomik durumu ve son olarak Komorlar Birliği'nin ekonomik durumundan bahsedilecektir.

Pierre Jacquemot'a göre frank bölgesi taraftarlarının temel argümanı, faydalanıcılarının ekonomik gelişimi için gerekli olan parasal istikrarı sağlamasıdır. Sistem, bölge ülkelerinde faaliyet gösteren ve yatırım ve faaliyeti teşvik etmesi beklenen özel ve kamu işletmecilerinin gelirlerini ve varlıklarını güvence altına almaktadır. Aslında, enflasyon riski uzun vadede her yerde azalmaktadır (Jacquemot, 2017:124).

\section{GSYİH'ye göre ekonomik büyüme}

UEMOA ülkelerinin ekonomik durumu 2018 yılında pek iyi gelişme gösterememiştir: Gayri Safi Yurtiçi Hasıla'nın büyüme oranı \%6,6'dır. UEMOA bölgesindeki reel GSYH büyüme oranı (yıllık ortalama, \%) Tablo 2'de özetlenmektedir.

2018'deki UEMOA bölgesinin GSYİH ortalaması \%6,6'dır. Bu GSYİH, 2015 ve 2016'ya göre biraz artmıştır. Togo, Mali ve Gine Bissau dışında, UEMOA bölgesinin tüm ülkeleri \%6'dan fazla bir ekonomik büyümeye sahiptir. Fildişi Sahili hala bölgedeki en yüksek ekonomik büyüme oranına sahiptir.

CEMAC'in GSYH'sinde \%1,5'lik bir düşüşle sonuçlanan 2016'daki büyük ölçekli petrol şokunun ardından, alt bölgedeki altı ülke Aralık 2016'daki Yaounde toplantısında bölgesel bir çıkış stratejisini kabul ederek uyum programlarının eşgüdümlü uygulanması konusunda anlaşmışlardır. 
Tablo 2. UEMOA bölgesindeki reel GSYH büyüme oranı (yıllık ortalama, \%)

\begin{tabular}{|l|c|c|c|c|}
\hline \multicolumn{1}{|c|}{ Ülke } & $\mathbf{2 0 1 5}$ & $\mathbf{2 0 1 6}$ & $\mathbf{2 0 1 7}$ & $\mathbf{2 0 1 8}$ \\
\hline Benin & 2,1 & 4,0 & 5,8 & 6,7 \\
\hline Fildişi Sahili & 8,8 & 8,0 & 7,7 & 7,4 \\
\hline Gine-Bissau & 6,1 & 6,2 & 5,9 & 3,8 \\
\hline Burkina Faso & 3,9 & 5,9 & 6,3 & 6,6 \\
\hline Mali & 6,2 & 5,8 & 5,4 & 4,9 \\
\hline Nijer & 4,3 & 4,9 & 4,9 & 6,5 \\
\hline Senegal & 6,4 & 6,4 & 7,1 & 6,7 \\
\hline Togo & 5,7 & 4,9 & 4,4 & 4,9 \\
\hline UEMOA & $\mathbf{6 , 3}$ & $\mathbf{6 , 4}$ & $\mathbf{6 , 6}$ & $\mathbf{6 , 6}$ \\
\hline
\end{tabular}

Kaynak: Rapport Annuel de la Zone Franc, 2018:35

Temmuz 2016 ile Temmuz 2019 arasında alt bölgedeki altı ülkeden beşi IMF ile finansman anlaşması imzaladı (biri Temmuz 2019'da). Ekvator Gine'si finansmansız bir anlaşma imzalamıştır. Mali kaynakların daha iyi seferber edilmesi ve kamu harcamalarının azaltılması yoluyla yapılan mali ayarlamalar, kamu dengeleri ve mal ve hizmet dengesinde (sirasiyla \%-4'ten \%-0,3'e ve \%-1,2'den \%2,6'ya kadar) belirgin bir iyileşmeye yol açmış ve döviz rezervlerinin dengelenmesine yardımcı olmuştur. Bölge, ham petrol fiyatlarının yükselmesi ve petrol üretiminin ardından 2018 yılında \%1,6 olan büyümeye geri dönmüştür. CEMAC, bir yandan zayıf ekonomik çeşitlilik, eğitime sınırlı erişim ve kırılgan bir iş ortamı, diğer yandan Çad, Orta Afrika ve Kamerun başta olmak üzere yüksek güvenlik riski gibi yapısal sorunlarla hala karşı karşıya kalmaktadır (Rapport de la zone franc, 2018: 67).

CEMAC bölgesindeki altı eyaletten beşi gelirlerini petrolden almasına rağmen, ekonomileri farklı profiller sunmaktadır. Tablo 3'te, CEMAC bölgesi ülkelerinin ekonomileri ilk olarak toplam GSYH ve sonra petrol dışı GSYH için analiz edilmiştir.

2018 yılında ekonomik aktivite, 2017 y1lında gözlenenlere göre \%1,6 artış göstermiştir. Petrol dış1 sektörün devam eden büyüme oranının ve petrol sektörünün 2018 yılında toparlanmasının ekonomik büyümedeki bu küçük artışı desteklediğini belirtmek önemlidir. Kamerun, 2018 yılında bölgedeki en yüksek GSYİH oranına sahiptir. CEMAC bölgesindeki oranların ekonomik büyümesi, UEMOA bölgesi ülkelerininkine kıyasla gerçekten kritik seviyededir.

Komor ekonomik büyümesi 2017'de \%3,5 den \%3,8'e ulaşmış bu artış 2018 yılında da devam etmiştir. Komorlarda, kişi başına GSYH'deki büyüme (yerel para biriminde sabit fiyatlar) önemli ölçüde düşüktü, 2017'de yaklaşı \%0,4'ten 2018'de \%0,5'e ulaşmıştır (Banque Mondiale, 2018). 
Tablo 3. CEMAC bölgesinde hacmine göre toplam GSYH ve petrol dışı GSYH büyüme oranı (\%)

\begin{tabular}{|c|c|c|c|c|}
\hline Ülke & 2015 & 2016 & 2017 & 2018 \\
\hline \multicolumn{5}{|l|}{ Toplam GSYH } \\
\hline Kamerun & 5,7 & 4,6 & 3,6 & 4,1 \\
\hline $\begin{array}{l}\text { Orta Afrika } \\
\text { Cumhuriyet }\end{array}$ & 4,3 & 4,8 & 4,5 & 3,9 \\
\hline Kongo & $-1,0$ & $-12,2$ & $-0,2$ & 1,4 \\
\hline Gabon & 3,9 & 2,0 & 0,5 & 0,4 \\
\hline Ekvator Ginesi & $-9,3$ & $-9,4$ & $-2,1$ & $-4,0$ \\
\hline Çad & 2,4 & $-3,4$ & $-4,7$ & 1,5 \\
\hline CEMAC & 1,4 & $-1,5$ & 0,6 & 1,6 \\
\hline \multicolumn{5}{|l|}{ Petrol diş1 GHYH } \\
\hline Kamerun & 4,4 & 5,3 & 5,0 & 4,5 \\
\hline $\begin{array}{l}\text { Orta Afrika } \\
\text { Cumhuriyet }\end{array}$ & 4,3 & 4,8 & 4,5 & 3,9 \\
\hline Kongo & 1,0 & $-14,6$ & $-4,3$ & $-12,0$ \\
\hline Gabon & 2,5 & 3,6 & 3,2 & 2,7 \\
\hline Ekvator Ginesi & $-2,2$ & $-10,0$ & 2,8 & 2,2 \\
\hline Çad & $-2,9$ & $-1,8$ & $-3,4$ & $-0,4$ \\
\hline CEMAC & 1,3 & $\mathbf{0 , 0}$ & 1,8 & 1,3 \\
\hline
\end{tabular}

Kaynak: Rapport Annuel de la Zone Franc, 2018: 68

Frank Bölge Raporu (2018)'na göre, GSYİH büyümesi, esas olarak, memurların maaş ve ücretlerinin (2018'de $+\% 3.4$ ) ve yatırım (Brüt sabit sermaye oluşumunda $\% 4,8$ artış) ile desteklenen nihai tüketim (2018'de +\% 5.0) ile açıklanmaktadır. 2016'dan 2018'e "Grande Comore" adasındaki büyük kamu yatırım programları ile, toplam yatırım oranı biraz artış göstermektedir (2016'da \%12,6, 2017'de \%12,9 ve 2018'de \%13)(Rapport de la zone franc, 2018: 97).

Mal ve hizmet ihracatı 2017 'den $(+\% 16,4)$ sonra yeni bir genişleme $(+\% 17,7)$ yaşamış özellikle dünya fiyatlarındaki yükseliş nedeniyle, artan dalgalanma gösteren üretimin etkilerini azaltmaya yardımcı olmuştur. Bununla birlikte, daha 1lımlı bir dinamiğe rağmen mal ve hizmet ithalatı hacmi yapısal olarak daha yüksektir (2018'de 2017'ye göre +\% 11,7). 2018 yılında, değer olarak sırasıyla, ara mallar \%50,4 (taşıtlar, yedek parçalar ve inşaat malzemeleri) ve petrol ürünleri ithalatı \%20,3 artmıştır (Rapport de la zone franc, 2018: 97).

\section{Ekonomi Politikaları}

Dünya Bankası, 2006'dan beri her yıl Ülke Politikası ve Kurumsal Değerlendirme "Country Policy Institional Assessment" (CPIA) yayımlamaktadır. CPIA'nın amac1, Uluslararası Kalkınma Derneği'nden "International Development Association" (IDA) destek almaya uygun ülkelere kredi ve hibe tahsisi için temel oluşturmaktadır (Jacquemot, 2017: 125). 
CPIA, bir ülkenin politikalarının ve kurumsal çerçevesinin kalitesini ölçmeyi amaçlayan bir teşhis aracıdır. Bu anlamda, ülkenin kontrolü dışındaki unsurlardan etkilenen sonuçlar (büyüme oranları gibi) yerine ülkenin üzerinde kontrol sahibi olduğu kilit unsurlar üzerinde durulmaktadır. Daha spesifik olarak, CPIA, bir ülkenin politikalarının ve kurumsal çerçevesinin sürdürülebilir büyümeyi ve yoksulluğun azaltılmasını ne ölçüde desteklediğini ve dolayısıyla kalkınma yardımlarının etkin kullanımını değerlendirmektedir (CPIA Afrique, 2019, p. 102). Tablo 4 Sahra altı Afrika'daki IDA ülkelerinin sıralamasını göstermektedir.

Tablo 4. Sahra altı Afrika'daki IDA ülkeleri

\begin{tabular}{l|l}
\hline Kırılgan & Kırılgan değil \\
\hline Burundi & Benin \\
Komorlar & Burkina Faso \\
Kongo, Tem. & Cabo Verde \\
Kongo, R.D. & Kamerun \\
Fildişi Sahili & Etiyopya \\
Eritre & Gana \\
Gambiya & Gine \\
Gine-Bissau & Kenya \\
Liberya & Lesotho \\
Mali & Madagaskar \\
Mozambik & Malawi \\
Orta Afrika Cumhuriyeti & Moritanya \\
Somali & Nijer \\
Sudan & Nijerya \\
Güney Sudan & Uganda \\
Çad & Ruanda \\
Togo & Sao Tome ve \\
Zimbabve & Principe \\
& Senegal \\
& Sierra Leone \\
& Tanzanya \\
& Zambiya \\
\hline Kay & 2019:93 \\
&
\end{tabular}

Kaynak: World Banque: CPIA Afrique, 2019: 93

Gabon ve Ekvator Ginesi hariç olmak üzere, frank bölgesi’ndeki tüm ülkeler IDA desteği için uygundur. Sahra altı Afrika'da en üst sıralarda yer alan ülkelerde Benin, Burkina-Faso, Kamerun, Nijer ve Senegal bulunurken Fildişi Sahili, Mali, Orta Afrika, Çad, Togo, Gine Bissau, Kongo ve Komorlar kırılgan statülü ülkelerde bulunmaktadır. Komorlar $(2,8)$, Kongo $(2,9)$, Gine Bissau $(2,5)$, Orta Afrika $(2,6)$ ve Çad $(2,7)$ gibi ülkeler, bölge ortalamasının altında olması nedeniyle "kırılgan" kategorisinde sınıflandırılmıştır. 2019'daki Fildişi Sahili (3.5), 2014'e kadar olan istikrarsızlığı nedeniyle "kırılgan" bölgede bulunmaktadır. 
Tablo 5. Afrika ülkesinin GSYIH (2019).

\begin{tabular}{|c|c|c|}
\hline Ülke & Suralama & GSYH (Milyon Dolar) \\
\hline Nijerya & 1 & 447.01 \\
\hline Güney Afrika & 2 & 385.53 \\
\hline Misir & 3 & 298.15 \\
\hline Cezayir & 4 & 200.17 \\
\hline Fas & 5 & 122.46 \\
\hline Angora & 6 & 110.19 \\
\hline Kenya & 7 & 98.26 \\
\hline Etiyopia & 8 & 88.17 \\
\hline Tanzanya & 9 & 60.30 \\
\hline Gana & 10 & 57.23 \\
\hline Libya & 11 & 51.33 \\
\hline Fildişi & 12 & 49.40 \\
\hline Kongo & 13 & 46.12 \\
\hline Tunus & 14 & 42.28 \\
\hline Kamerun & 15 & 40.13 \\
\hline Uganda & 16 & 29.87 \\
\hline Zambiya & 17 & 26.12 \\
\hline Zimbabve & 18 & 21.63 \\
\hline Senegal & 19 & 26 \\
\hline Botsvana & 20 & 19.78 \\
\hline
\end{tabular}

Kaynak: Agence d'Information d'Afrique Centrale, 2019

\section{Frank Bölgesi ve Diğer Afrika Ülkeleri}

Frank bölgesi ülkelerinin ekonomik durumunu daha iyi tartışabilmek için, ekonomik durumunu frank bölgesinde olmayan diğer ülkelerin durumlanyla karşılaştırmak önemlidir. Tablo 5'te 2019'daki 20 Afrika ülkesinin GSYİH'si sunulmaktadır.

Tablo 5'ten, frank bölgesindeki hiçbir ülkenin GSYİH'si en yüksek 10 Afrika ülkesi arasında olmadığı görülmektedir. Nijerya, Güney Afrika, Mısır, Cezayir, Angola, Etiyopya, Kenya, Fas, Tanzanya, Tunus gibi ülkeler Fildişi'nden daha yüksek GSYİH'ye sahiptir. Fildişi'nin frank bölgesinde GSYİH açısından ilk sırada yer aldığını belirtmek önemlidir. Bu sınıflandırmada frank bölgesinin sadece dört ülkesi vardır. Frank bölgesindeki bu sıralamadaki ilk ülke Libya'nın arkasındaki on ikinci sırada yer almaktadır.

Özetle, UEMOA bölgesi ülkeleri, ekonomik olarak CEMAC bölgesi ve Komor ülkelerine göre biraz daha istikrarlı olsa bile, frank bölgesinin durumunun biraz kritik olduğunu söyleyebiliriz. Frank bölgesindeki hiçbir ülke Afrika'da yüksek GSYİH'ye sahip ilk 10 ülke arasında yer almamaktadır ve frank bölgesinde ilk 20 ülke sıralamasında sadece dört ülke bulunmaktadır. Cezayir, Fas ve Tunus gibi 
frank bölgesinden ayrılan ve kendi para birimlerine sahip olan ülkelerin frank bölgesindeki bazı ülkelere kıyasla ekonomik olarak daha iyi olduğunu söylemek mümkündür. Dolayısıyla, parasal bağımlılık ekonomik büyüme ve kalkınmada önemli bir rol oynamaktadır. Bu nedenle, frank bölgesi ülkelerinin ekonomik faaliyet üzerinde kontrol sahibi olabilmek için kendi para birimlerine sahip olmaları önemlidir.

Gabon ve Ekvator Ginesi hariç olmak üzere, Frank Bölgesi'nin tüm ülkeleri, ağır borçlu fakir ülkeler grubuna ve IDA desteği almaya uygun ülkeler grubuna dahil edilmiştir. Buna ek olarak, Birleşmiş Milletler'in (UN) En Az Gelişmiş 46 Ülkesi arasında 33'ü Afrika ülkeleri ve dokuzu frank bölgesindendir (UNCTAD, [n.d]).

UNDP İnsani Gelişme Raporu'na (2015) göre, frank bölgesindeki 13 ülke, insani gelişmenin düşük olduğu ülkeler grubundadır. Bunlar Kamerun (153.), Komorlar (159.), Togo (162.), Benin (166.), Senegal (170.), Fildişi Sahili (172.), Kongo (176.), Mali (179.), Gine Bissau (178.), Burkina (183.), Çad (185.), Orta Afrika (187.) ve Nijer (188.)'dir. Dünyadaki insani gelişimi düşük olan son iki ülkenin Orta Afrika ve Nijer olduğunu belirtmek önemlidir (UNDP, 2015: 28-31).

Dört yıl sonra durum hala aynı şekilde bulunmaktadır. Hiçbir gelişme olmamıştır. UNDP İnsani Gelişme Raporu'na (2019) göre Kamerun dışında frank bölgesindeki 12 ülke hala insani gelişmenin düşük olduğu ülkeler grubundadır. Çad (187.), Orta Afrika (188.) ve Nijer (189.) dünya sıralamasında son sirada yer almaktadır (UNDP, 2019: 24-27).

Frank bölgesi sistemi kalkınma yerine sadece Afrika'ya yoksulluk getirmektedir. Ancak bu gözlem, CFA frangı savunucuları ve partizanları, ekonomik büyüme oranının sağlamlığından bahsetmek için kendilerini UEMOA bölgesinin performanslarına dayandırsa bile çok açıktır. Ancak bu performanslar gerçekte suları gereksiz yere çamurlayan bir manipülasyon şeklidir. Frank bölgesinin bu üye ülkeleri, ekonomik büyüme oranlarının sağlamlığına rağmen geride kalmaktadır.

\section{CFA FRANGI: AVANTAJLARI VE DEZAVANTAJLARI ÜZERINDE BİR TARTIŞMA}

\section{CFA frangı'nın avantajları}

CFA frangı'nın avantajları hakkında ileri sürülen ana argüman, üye ülkeleri için ekonomik istikrarı garanti etmesidir. Bu kısım, CFA frangı kullanmanın yararlarını ele almakla ilgilidir.

CFA frang1 kullanmanın ilk avantajı döviz kurudur. CFA frangı döviz kuru sadece Euro döviz kuruna göre değişmektedir. Bu nedenle bu para birimini kullanan ülkeler, sadece biraz daha istikrarlı olan Euro döviz kurunun evrimine baktıklarından, ithalat ve ihracattaki döviz kurunun evrimini umursamamaktadır. Ancak bu avantaj yalnızca CFA frangı kullanan ülkelerde kalmaktadır.

İkinci avantaj enflasyonda bulunmaktadır. CFA frangı kullanan ülkeler s1klıkla hiperenflasyon problemleriyle karşılaşmazlar. Nitekim, bu ülkeler \%2'yi aşmaması gereken bir enflasyon oranı hedefine sahip olduklarından üye ülkeler içerisinde istikrarlı fiyatlara sahiptirler. Öte yandan, Fransız hazinesi tarafından garanti edilen avroya dönüştürülebilirlik vardır, yani CFA frangı herhangi bir zamanda avroya dönüştürülebilmektedir. Bir avantaj olarak, transfer özgürlüğünü de ifade edebiliriz. Fransız hazinesi Euro bölgesinde transfer özgürlüğünü garanti etmektedir. Bu nedenle, varlıklarını herhangi bir zamanda Euro bölgesine transfer etmeyi garanti eden Fransız şirketleri, frank bölgesine yatırım yapmayı cazip bulabilmektedirler (Claveres, 2017: 3).

\section{CFA frangı'nın dezavantajları}

CFA frangı'nın mevcut işleyişine en büyük eleştiri üye ülkelerini tüm parasal bağımsızlıktan mahrum etmesidir. Para politikası kararları Fransa Bankası tarafından onaylanmaktadır. Bütçe 
egemenliği de bir dizi gözetim mekanizması tarafından güçlü bir şekilde çerçevelenmektedir. Kendi başına, bazı ülkelerin varsayımlara dayalı genişletici politikalar uygulamaktan ya da buna karar verdiği için fayda sağlayacağını düşünebiliriz. Örneğin, bu gözetim, bir hükümetin yatırım projelerini finanse ederek kamu harcamalarıyla Keynesyen bir teşvik politikası uygulamasını engelleyebilmektedir. Bu nedenlerle, CFA frangı ülkelerini (ve daha genel olarak frank bölgesi) Fransa ve Euro ile ilişkilendiren kurumsal düzenlemenin parasal bir denetim olduğu düşünülmektedir (Claveres, 2017: 5).

Parasal bağımlılık sorunu, üye ülkelerin ekonomik kalkınması için gerçek bir engel oluşturabilmektedir. Frank bölgesinin üye ülkeleri rezervlerinin bir kısmını Fransız hazinesine bırakmaktadır. Bu onları yatırımlar için likiditeden mahrum edebilmektedir. Buna ek olarak, bu devletler ihracatta rekabetçi değildirler çünkü paralarının maliyetini kontrol etmezler ve CFA frangı, güçlü bir para birimi olan Euro karşısında değişim göstermektedir. Bu nedenle para birimlerinin zayıf olduğu ülkelere ihracatta sorun yaşayabilmektedir.

Döviz kuru sabit, konvertibilite garantisi sınırsız ve sermayenin hareketi serbest olduğu için yatırımcılar için Euro bölgesine yatırım yapmak frank bölgesine yatırım yapmaktan daha cazip olabilmektedir. Bu, frank bölgesinde aktivite yaratmayı yavaşlatabilmektedir. Euro ile pariteyi sağlamak için ülkeler enflasyon oranlarını kontrol etmektedir. $\mathrm{Bu}$, ulusal bankaları işletmelere verilen kredileri sinırlamaya zorlamaktadır. Kredilerin bu şekilde sınırlandırılması, üye ülkelerdeki yatırımların azalmasını gerektirebilmektedir. Bu da altyapı eksikliğine yol açıp ekonomik büyümeyi olumsuz etkileyebilmektedir.

Üye ülkeler tek bir para birimiyle (CFA frangı) bağlantılı olduğundan, kriz zamanındaki ülkeler ihracatı daha rekabetçi hale getirmek için para birimlerini devalüe edememektedirler. Ek olarak, frank bölgesi ülkeleri tarafından ihraç edilen ürünler, Euro ile karşılaştırıldığında zayıf bir para birimi olan dolar cinsinden sabit fiyatlarla satılmaktadır. Euro'ya eklenen CFA frangı ile bu ülkelerin gelirleri zayıf para biriminde ve harcamaları güçlü para birimindedir. Bu, ülkeler için ekonomik bir tehlike oluşturabilmektedir.

\section{SONUÇ VE DĞERLENDİRME}

$\mathrm{Bu}$ çalışmada CFA Frangı para sisteminin Afrika ülkeleri üzerindeki ekonomik etkilerinin incelenmesi amaçlanmıştır. CFA frangı, Batı ve Orta Afrika'daki Fransızca konuşan ülkeler için ortak para birimidir. Frank bölgesi, Fransa sömürgelerinin ekonomik faaliyetinin içinde gerçekleştirildiği çağdan kaynaklanan bir sistemdir. 75 yıllık varlığı boyunca, Fransız kolonilerinin bağımsızlı̆̆ına rağmen CFA frangı korunmuştur. CFA frangı sisteminin temel amacı fiyat istikrarını sağlamaktır. Bununla birlikte, CFA frang1 sistemi, ülkelerin ekonomik büyümeyi arttırmaya ve daha rekabetçi olmaya çalıştıkları mevcut ekonomik bağlamda üye devletler için artık yeterli görülmemektedir.

Sadece bir devlet para birimini seçme gücüne sahiptir. Böylece, parasal manipülasyon yoluyla, başka bir devletin anlaşmasını veya görüşünü sormadan para biriminin değerini değiştirebilir. Devletler bu nedenle kendi para birimlerini yaratmakta özgürdürler. Aynı şekilde, para birimi bir ülkenin kimliğini belirlemektedir. Para biriminin kontrolü, sürdürülebilir ekonomi politikası ve kalkınma için önemlidir. $\mathrm{Bu}$ perspektiften, frank bölgesinin üye ülkelerinin parasal bağımlılıklarının gelişmelerinde bir fren olduğunu söyleyebiliriz. Aslında, her yıl Fransız hazinesine rezervlerinin \%50'sini ödedikleri için kapasitelerinin $\% 50$ 'si ile yükümlüdür. Böyle bir durumda, bu ülkelerin ciddi bir ekonomi politikas1 uygulaması imkansızdır. Kalkınmayı teşvik etmek için, bu ülkeler kendi para birimlerini yaratarak, kriz dönemlerinde paralarını devalüe ederek ve aynı zamanda enflasyonun bir miktar yükselmesine izin vererek akıllı bir ekonomi politikası uygulamalıdır. 
CFA frangı sadece Afrika ekonomilerinin gelişimini engellemek için kurulmuş bir sistemdir. Birincisi, CFA frangının çalışma prensipleri eskidir ve artık mevcut ekonomik koşulları karşılamamaktadır. CFA frangı sistemi, üye ülkeleri geliştirmek yerine onları daha da yoksullaştırmaktadır. Böyle bir teoriyi anlamak için, frank bölgesinin üye ülkelerinin ekonomik büyüme hızının diğer devletlere kıyasla evrimine bakmak yeterlidir. Frank bölgesindeki hiçbir ülke, Afrika'nın GSYİH'si yüksek olan ilk 10 ülkesi arasında yer almamaktadır. Aslında, frank bölgesi ülkeleri, ekonomik büyümenin ve özellikle UEMOA bölgesinin sağlamlığına $(2018$ 'de \%6,6) rağmen önemli bir ekonomik büyüme gecikmesine sahiptir. İkinci olarak, CFA frangının gelişimlerini desteklemek yerine Afrika ülkelerini yoksullaştıran bir sistem olduğunu söyleyebiliriz. Aslında, Gabon ve Ekvator Gine'si hariç, frank Bölgesi'nin tüm ülkeleri, büyük ölçüde borçlu olan fakir ülkeler grubuna ve IDA desteği almaya uygun ülkeler grubuna dahil edilmiştir. Ayrıca, frank bölgesindeki dokuz ülke BM tarafından en az gelişmiş ülkeler (LDC) olarak sınıflandırılmıştır. UNDP İnsani Gelişme Raporuna göre, frank bölgesindeki 13 ülke, 2015 yılında düşük insani gelişme gösteren ülkeler grubunda yer almaktadır ve Kamerun bu listeden çıkarılsa bile durum 2019'de aynı kalmaktadır. Bu ülkeler, güçlü ekonomik büyüme oranına rağmen kalkınma merdiveninin en altında bulunmaktadır. Ekonomik büyümenin sağlamlığından bahsetmek için UEMOA bölgesinin performanslarına dayanarak, frank bölgesinin ekonomik durumundaki gerçekler gizlenmektedir. Üçüncü olarak, CFA frangının Fransa'nın frank bölgesinin üye devletleri üzerindeki hakimiyet ve kontrol arac1 olduğu söylenebilmektedir. Aslında, CFA frangı üzerinde kontrol sahibi olmak için, CFA frangı Fransa'da basılmaktadır. Aynı zamanda, Fransız hakimiyeti, Fransızların BCEAO Yönetim Kurulunda bulunmasıyla da görülebilir.

Frank bölgesinden ayrılmak üye ülkeler için önemlidir. Bu ülkelerin kalkınmaları için sürdürülebilir ve ciddi ekonomi politikaları oluşturmak amacı ile finansal açıdan bağımsız olmaları gerekmektedir. Kako Nubukpo'nun söylediği gibi CFA frangı bir "gönüllü kulluk aracıdır" (Nubupko, 2007). Yani üye devletler, Fransa ile olan ticari ilişkilerini kaybetme korkusu ya da kendi para birimlerinin oluşturulmasını takiben başarısızlık korkusu nedeniyle, frank bölgesinden ayrılmak istememektedir. Ancak CFA frang1, Fransa ile ticareti şart koşan bir araç olmak zorunda değildir. Cezayir, Fas ve Tunus gibi ülkeler frank bölgesinden ayrılmış olup şu ana kadar Fransa ile iyi ticari ilişkilere sahiptirler. Cezayir, Nijerya, Tunus ve Fas, Fransa'nın başlıca Afrika ihracatçılarıdır. Frank bölgesinden ayrılan bu ülkeler (Cezayir, Fas ve Tunus) GSYİH açısından frank bölgesinin birincisi olan Fildişi Sahili'nden daha yüksek bir GSYİH'ye sahiptir. Yani kalkınma talebinde bulunmak için Afrika ülkelerinin frank bölgesinden ayrılması veya CFA frangı sisteminin çalışma prensiplerini tamamen değiştirmesi gerekmektedir. 


\section{KAYNAKÇA}

Avom, D. \& Noumba, I. (2019). La résilience de la zone Franc à l'épreuve des critiques persistantes . Revue Interventions économiques, 61(1): 6-29.

La zone franc (16.09.2016). Banque de France. Erişim Adresi: https://www.banque-france.fr/economie/relationsinternationales/partenariats-afrique-france/cooperations-afrique-france. Erişim tarihi: 06.11.2020.

Claveres, G. (2017). Le franc cfa à l'heure des choix. BSI Economics. Erişim Adresi http://www.bsieconomics.org/746-franccfa-bsi-enjeux-gc Erişim tarihi: 06.11.2020.

Coquet, B. \& Daniel, J. M. (1992). Quel avenir pour la zone franc?. OFCE, Observations et diagnostics économiques $\mathrm{n}^{\circ} 41$ /juillet: $243-244$.

CPIA Afrique (2019). Renforcement de la capacité de la gestion de la dette. Erişim Adresi: http://documents1.worldbank.org/curated/en/553221564513028077/pdf/Country-Policy-and-InstitutionalAssessment-CPIA-Africa-2018-Strengthening-Debt-Management-Capacity.pdf.

Diallo, O. (2002). L'arrimage du franc CFA à l'euro: Conséquences pour l'intégration sous-régionale ouestafricaine. Institut européen de l'Université de Genève, vol. 15. Erişim Adresi https://www.files.ethz.ch/isn/145618/15_diallo.pdf. Erişim tarihi: 08.11.2020

Jacquemot, P. (2017). Le procès de la Zone franc. Arguments, contre-arguments et voies d'évolution. Mondes en développement, 4(180):121-140.

Kebe, M. L. (2019). Le Franc CFA, le néocolonialisme à l'épreuve du développement. Public and International Affairs - Research Papers, Ottawa university.

Lelart, M. (1985). Le système monétaire européen et le système monétaire francoafricain. Ed. La Découverte. Eurépargne, $n^{\circ} 11$ et 12 . Collection Reperes: France

Ndong, N. (19.12.2019). Afrique : top 20 des pays les plus riches en 2019. Agence d'information d'Afrique centrale. http://www.adiac-congo.com/content/afrique-top-20-des-pays-les-plus-riches-en-2019-110332. Erişim tarihi: 09.11.2020.

Nubukpo, K. (2007). Politique monétaire et servitude volontaire: la gestion du franc CFA par la BCEAO. Politique Africaine, 1(105): 70-84.

Rapport annuel de la zone franc (2018). Banque de la France. https://publications.banquefrance.fr/sites/default/files/medias/documents/819174_zf2018_web_signets_avec-couv1.pdf. Erişim tarihi: 14.11.2020.

Rapport sur le développement humain (2015). Le travail au service du developpement humain. PNUD. http://hdr.undp.org/sites/default/files/2015_human_development_report_overview_-_fr.pdf. Erişim tarihi: 14.11.2020.

Rapport sur le développement humain (2019). Au-delà des revenus, des moyennes et du temps présent: les inégalités de développement humain XX siècle. http://hdr.undp.org/sites/default/files/hdr_2019_overview_-_french.pdf. Erişim tarihi: 14.11.2020.

Servet, J. M. (2012). Les monnaies du lien. Presses universitaires de Lyon: Lyon

Sulkowski, J. (1929). Questions juridiques soulevées dans les rapports internationaux par les variations de valeur des signes monétaires. Recueil des cours (Académie de droit international), 29 (IV):30-31.

Tchouassi, G. (2016). Le franc cfa, monnaie de la colonisation, de la communaute et de la cooperation : quel avenir?. Institutionnalismes monetaires francophones : bilan, perspectives et regards internationaux: 1-20.

UNCTAD (2018). List of least developped countries. Erişim Adresi https://unctad.org/topic/least-developpedcountries/list. Erişim tarihi: 17.01.2021.

UNDP (2015) . Insani Gelişme Raporu 2015. Erişim Adresi https://www.tr.undp.org > docs > Publications > hdr

UNDP (2018) . Insani Gelişme Raporu 2018. Erişim Adresi https://www.tr.undp.org > docs > Publications > hdr 


\section{EXTENDED ABSTRACT}

The CFA franc is a colonial currency created in 1945 by France to have control over these colonies. The CFA franc is used between 14 African countries and Comoros. In the context of the global currency war, debates are intensifying as to whether it is important to protect this common currency used in 14 African countries. The question of the future of the CFA franc has intensified in recent years. There are several reasons for this repetitive criticism. One of them is monetary dependence, which does not allow the member states to have control over the currency in circulation. This prevents them from implementing a sustainable economic policy. There are many other reasons such as the domination and control of France over the member states of the franc zone. In the literature, there are many studies (Coquet and Daniel, 1992; Diallo, 2002; Tchouassi, 2016; Claveres, 2017; Jacquemot, 2017; Avom and Noumba, 2019; Kebe, 2019) about the CFA franc. Most of these studies concern criticisms of the use of the CFA franc by member countries and the advantages and disadvantages of the CFA franc on their economy.

This study aims to examine the economic effects of the CFA franc monetary system on African countries. In the study, firstly, colonial monetary systems were examined as part of the historical process. Next, the functioning of the CFA franc monetary system, the current economic situation of countries using the CFA franc, and the advantages and disadvantages of the CFA franc within the economies of the user countries were explained. The last section provides an overview of the economic effects of the CFA franc monetary system.

Research-based on data and information relating to the current economic situation in countries using the CFA franc are carried out. To analyze the current economic situation in the countries using the CFA franc, data relating to economic growth, to the economic policies of these countries was examined. A comparison of the economic situation of member countries with non-member countries was also made. Finally, a discussion on the advantages and disadvantages of the CFA franc in the economies of the user countries are discussed through data and information obtained from numerous professional reports and studies carried out by institutions, researchers, and/or academics.

In this paper, we find that even if the countries of the UEMOA zone are a little more stable economically than the CEMAC zone and Comoros, the situation in the franc zone is somewhat critical. No franc zone country is among the top 10 high GDP countries in Africa, and there are only four franc zone countries in the top 20 high GDP countries in Africa. We also find that except Gabon and Equatorial Guinea, all countries in the franc zone are included in the group of heavily indebted poor countries and the group of countries eligible for IDA support. Also, among the 46 least developed countries of the United Nations (UN), 33 were African countries and nine were from the franc zone (UNCTAD). According to the UNDP Human Development Report (2015), 13 countries in the franc zone are part of the group of countries with low human development. Four years later, the situation is still the same. There has been no improvement. According to the same report (2019), 12 countries of the franc zone except Cameroon, are still part of the group of countries with low human development. 